\title{
Melhores práticas em sistemas locais de saúde: sob foco, a saúde bucal do idoso*
}

\section{| ${ }^{1}$ Ana Lúcia Schaefer Ferreira de Mello, ${ }^{2}$ Samuel Jorge Moysés |}

Resumo: Objetivou-se desenvolver melhores práticas no cuidado à saúde bucal de pessoas idosas, por meio do referencial Modelo de Domínios Interativos de Melhores Práticas em Promoção da Saúde (MDI), que considera a interação de domínios (Fundamentos, Compreensão do Ambiente e Práticas) como fatores de decisãoação, subsidiando os fundamentos desta pesquisa-ação. Efetivou-se uma intervenção em um sistema municipal de saúde, por meio de reflexão participativa entre atores locais envolvidos com a governança pública local, examinando sua potência para transformar práticas correntes segundo princípios da Promoção da Saúde. A coleta de dados foi realizada por multiestágios, iniciando com grupos focais compostos por gestores, profissionais de saúde e idosos. A partir das deliberações dos grupos focais e análise dos dados mediante o marco lógico adotado, foram propostas melhores práticas, fundamentadas nos princípios do Sistema Único de Saúde, da Estratégia de Saúde da Família e da Promoção da Saúde. O conjunto $\mathrm{da}$ intervenção envolveu algumas atividades práticas. $\mathrm{O}$ processo de desenvolvimento de melhores práticas sustenta-se na expectativa de que um melhor padrão de saúde bucal dos idosos poderá ser alcançado mediante mudança de práticas organizacionais, do processo de trabalho em saúde, de pesquisa e de avaliação. $\mathrm{O}$ vetor de impulsão para melhoria contínua é o compromisso da governança local com a sustentabilidade e aprofundamento dos princípios da Promoção da Saúde. Demonstrou-se ser possível construir um corpo indicativo de práticas de cuidado à saúde bucal das pessoas idosas e gerar conhecimento útil que aproxima os modelos teóricos com a realidade cotidiana, com vistas a sua transformação.

> Palavras-chave: atenção à saúde, saúde do idoso, saúde bucal, serviços de saúde para idosos, sistemas de saúde, promoção da saúde.

\author{
'Doutora em Odontologia \\ em Saúde Coletiva; \\ professora do Departamento \\ de Odontologia da UFSC. \\ Endereço eletrônico: alfm@ \\ terra.com.br \\ ${ }^{2}$ Doutor em Epidemiologia e \\ Saúde Pública; professor do \\ Programa de Pós-graduação \\ em Odontologia da UFSC e da \\ PUC-PR. Endereço eletrônico: \\ s.moyses@pucpr.br
}

Recebido em: 08/07/2009 Aprovado em:30/03/2010 
O cuidado à saúde bucal implica, nas esferas individual e coletiva, um processo dinâmico e contínuo de reconhecimento da influência das condiçôes bucais em diversas dimensões da vida. Esta é a perspectiva de Botazzo (2006), quando propõe a superação da visão odontológica, restrita aos limites dento-gengivais e de suas condições de saúde e doença, e, em consequência, o reconhecimento da "produção social" imanente à bucalidade do ser humano, compreendida em pelo menos três dimensões da vida em sociedade: manducação, linguagem (comunicação) e erótica. Esse conceito de bucalidade entende a boca como território que, por sua condição de produção e consumo, definidos culturalmente, apresenta contornos e configuraçōes diferenciados, tornandose objeto também das ciências humanas e sociais. Trata-se de uma construção cotidiana que pressupõe uma visão integral do ser humano e das suas relações com outros seres, com as organizações de saúde, com a sociedade e com o meio ambiente (MELLO, 2007).

É nesse outro campo das ciências que se encontram explicações para o fato de que o domínio da dimensão técnica de procedimentos odontológicos e linhas de conduta clínica, ambos com avanços expressivos, não asseguram automaticamente uma melhor condição de saúde bucal das populações, do ponto de vista epidemiológico. Os males que afetam a saúde bucal, e particularmente, a saúde bucal do idoso, derivam decisivamente de determinantes socioeconômicos, culturais, ambientais, comportamentais e organizacionais, que definem o tipo, os níveis e a gravidade das doenças bucais - ou seja, o respectivo padrão epidemiológico. Neste sentido, a literatura epidemiológica em saúde bucal traz à tona alguns questionamentos e dúvidas sobre a atual prática assistencial odontológica (NARVAI et al., 2006), na expectativa de que se amplie o acesso e a resolutividade orientados para o cuidado à saúde bucal.

De fato, a apropriação social dos conhecimentos científicos em saúde bucal depende da superação do distanciamento entre o saber acumulado e a prática corrente oferecida à população, não raro, nem oferecida. Este é um paradoxo: a incapacidade de levar aos necessitados os melhores processos de cuidado que a evidênc ia científica pode proporcionar (GREEN, 2001). Apesar das leis, das políticas, das intençôes, o acesso dos idosos brasileiros ao oportuno e integral 
atendimento em saúde bucal, provido pelo Estado, frustra-se ante a insuficiência

de cobertura. Trata-se da grande distância observável entre a retórica institucional e a prática da oferta em face da demanda. Os serviços públicos mostram-se despreparados para suprir esta demanda, juridicamente assegurada, mas não traduzida em acessibilidade e resolutividade.

Portanto, bem distantes da oferta efetiva de assistência e de atenção à saúde bucal aos idosos, situam-se tanto o saber científico disponível como o conjunto normativo-retórico que promete assegurar o direito a essa provisão. Mesmo na esfera estrita da assistência clínica, os limitados serviços públicos de saúde bucal, por não ofertarem uma gama mais ampla de procedimentos na atenção básica ou mesmo de média complexidade, como os reabilitadores, circunscrevem a prática assistencial à livre demanda, tornando-a, devido à escassez de meios, pouco conservadora e até mesmo mutiladora (FERREIRA et al., 2006). Tais restrições são indutoras da perpetuação da demanda sintomática, cuja extração dentária é a única "porta de saída". Sabe-se que a ausência dentária pode acarretar graves consequências, independentemente da idade, especialmente se considerarmos o contexto da bucalidade já referido. Por outra parte, em face da ampliação da expectativa de vida, manter a população idosa descuidada, resulta adicionar novos e graves problemas de saúde, especialmente periodontais, de cárie de raiz e deficiências nutricionais (MARIÑO, 1994).

Fatos como a edição do Estatuto do Idoso, a formação de Equipes de Saúde Bucal (ESB) na Estratégia Saúde da Família (ESF), a implantação de Centros de Especialidades Odontológicas (CEO) e outras iniciativas de boas práticas no âmbito de alguns municípios e estados são sinais positivos. Contudo, é epidemiologicamente preocupante a carga de doença bucodental acumulada e o respectivo fluxo previsível da demanda nos anos à frente. A insuficiência de políticas de compressão da morbidade e a fragilidade dos sistemas de apoio aos idosos, mais o padrão medicalizante e hospitalocêntrico dos serviços, têm configurado um cenário no qual a demanda por cuidado à saúde dos idosos, incluída a saúde bucal, só ocorre por ocasião da necessidade iminente de intervenção para tratar problemas instalados. Mesmo sendo precárias as condições de saúde bucal da população idosa, e volumosas as suas necessidades acumuladas, a utilização dos serviços odontológicos ainda é pequena (MARTINS, 2008). 
Durante muitos anos, a atenção pública à saúde bucal no Brasil organizou-se de forma paralela e afastada da estruturação dos demais serviços que compunham o sistema de saúde. Atualmente, há uma tendência à integração que conjuga a saúde bucal aos demais saberes e práticas, na perspectiva da promoção e vigilância em saúde, numa abordagem familiar e de defesa da vida e da dignidade humana (BRASIL, 2006). Imaginar a construção de melhores práticas, inovadoras e resolutivas, num ambiente social complexo como o que se vive, implica imaginar também um outro cenário para as relações que se estabelecem entre o Estado e a sociedade, entre os governos e os cidadãos, entre as organizações públicas, privadas e as do terceiro setor. Neste sentido, Santos (1997) afirma que os requisitos políticos, societais, organizacionais e gerenciais que tornem a ação pública eficaz e eficiente no enfrentamento de problemas constituem razão para um novo enfoque gerencial no campo da administração pública.

Segundo Sá (2001, p. 155), as teorias no campo do planejamento e da gestão "têm abandonado progressivamente a visão positivista, presente em suas origens, e assumido uma perspectiva mais crítica, onde a dimensão política do problema ganha destaque". Para a autora, o desenvolvimento da autonomia dos sujeitos nas organizaçôes de saúde é uma das condiçôes fundamentais para a melhoria da gestão e "construção de projetos coletivos e solidários", o que permitiria uma validação ética e social. Neste contexto, a descentralização das ações de saúde no bojo do SUS, embora não assegure automaticamente melhorias na entrega dos serviços (CHAVES et al., 2007), proporciona rica oportunidade para que as comunidades conduzam uma forma de governança pública, capaz de avaliar corretamente as práticas correntes e encaminhar soluções criativas, participantes e de compromisso sobre os problemas. Segundo Ibanhes et al. (2007, p. 577, 583), a governança enquanto conceito que incorpora "novos atores e demandas sociais" se mostra como "uma possibilidade importante no debate, acesso, formulação, implementação e avaliação das políticas públicas, num contínuo qualitativo quanto ao exercício e efetivação de democracia social em nosso país.” A governança, nesta perspectiva, é considerada uma variável intermediária, pois "por um lado produz efeitos sobre uma variável dependente (exemplo: acessibilidade aos serviços de saúde), e por outro depende de variáveis independentes que a determinam (exemplo: a organização institucional do sistema de saúde)" (HUFTTY et al., 2006, p. S38). 
$\mathrm{Na}$ sociedade contemporânea, o processo de cuidar é fundamentalmente mediado por organizações de saúde. Portanto, a construção de pontes para reduzir a distância entre o conhecimento disponível e o ser humano necessitado, entre o direito à saúde legislado e o exercício do direito institucionalizado, de modo a permitir a produção de práticas adequadas, é hoje dependente da capacidade das organizações, particularmente as públicas, de adotarem tecnologias apropriadas de gestão que privilegiem a melhoria contínua das práticas. Esse deslocamento da responsabilidade pela tarefa do cuidado em saúde (bucal inclusive) para o universo das organizações formais, especialmente as organizaçôes públicas, está a exigir maior atenção para os aspectos associados à governabilidade institucional e governança das boas práticas em saúde (IBANHES et al. 2007). Assim, é oportuno experimentar tecnologias de gestão, no contexto de uma nova governança pública (KISSLER et al. 2006), que possibilitem construir melhores práticas em saúde bucal para idosos, em sistemas locais de saúde. O Health Promotion's Best Practice Work Group, sediado na Universidade de Toronto, definiu melhores práticas em saúde como: "o conjunto de ações e atitudes contínuas que são orientadas para alcançar os objetivos da promoção da saúde em determinada situação, e que são consistentes com os valores da promoção da saúde" (KAHAN et al., 2005, p. 8). De acordo com o marco conceitual desenvolvido por este grupo, as práticas serão consideradas "melhores" se forem consistentes e refletirem as bases/fundamentos da promoção da saúde e a compreensão do ambiente. Julga relevante, para isso, considerar aspectos como valores, objetivos e a ética da promoção da saúde, teorias e crenças, evidências e a adequação/compreensão do ambiente (KAHAN et al., 2001 e 2005).

As práticas de saúde constituem "as formas pelas quais a sociedade estrutura e organiza as respostas aos problemas de saúde" (WESTPHAL, 2006, p. 662). Assim, o conceito-paradigma da Promoção da Saúde poderá favorecer o questionamento da prática atual, redirecionando os procedimentos de ação coletiva para fazer valer seus valores e princípios como: integralidade das ações, equidade, intersetorialidade, participação social, empoderamento autonomia e sustentabilidade (WESTPHAL, 2006). Por operar numa perspectiva de saúde coletiva e por colocar em relevo o planejamento em saúde que utiliza métodos participativos, identificou-se no "Modelo de Domínios Interativos de Melhores 
Práticas em Promoção da Saúde, Saúde Pública e Saúde das Populações - MDI” (Interactive Domain Model of Best Practices for Health Promotion, Public Health and Population Health), desenvolvido na Universidade de Toronto (Canadá), uma ferramenta útil para a gestão. Seus fundamentos e metodologia se ajustam à pesquisa-ação que foi levada a cabo (KAHAN et al., 2001 e 2005).

A partir dessas premissas, objetivou-se neste estudo empregar melhores práticas no cuidado à saúde bucal de pessoas idosas, em um sistema municipal de saúde, por meio do referencial MDI de Melhores Práticas em Promoção da Saúde. Simultaneamente, procedeu-se a uma reflexão sistemática e crítica entre os atores envolvidos com a governança local, examinando sua potência para transformar as práticas correntes segundo os princípios da Promoção da Saúde.

\section{Métodos}

O projeto referente a esta pesquisa foi submetido e aprovado ao Comitê de Ética em Pesquisa com Seres Humanos da Universidade Federal de Santa Catarina, segundo Parecer no 264/2006. Todos os participantes que aceitaram contribuir com o estudo foram esclarecidos sobre os objetivos da pesquisa e sua metodologia, e foram solicitados a manifestar sua concordância por meio da assinatura do Termo de Consentimento Livre e Esclarecido.

O estudo apresentado, ao eleger o MDI como ferramenta para desenvolver melhores práticas de promoção à saúde bucal de idosos, adentrou pelo campo das tecnologias de gestão, submetendo ao teste de realidade um modelo de decisãoação. O objetivo do MDI é auxiliar pessoas envolvidas na gestão de serviços de saúde, em diferentes níveis de atuação (pesquisa, formulação de políticas ou implementação de ações), a refletir sistemática, integral e criticamente sobre suas práticas, e consequentemente transformá-las (KAHAN et al., 2001). O modelo é composto por três domínios: Fundamentos, Compreensão do Ambiente e Prática. Cada um destes domínios engloba subdomínios. O domínio Fundamentos inclui os subdomínios Valores, Objetivos, Preceitos Éticos, Teorias, Crenças e Evidências. O domínio Compreensão do Ambiente inclui os subdomínios Visão e Análise Situacional da Saúde e da Organização. O domínio Prática inclui os processos, atividades e estratégias dos subdomínios Saúde, Organização e Pesquisa/Avaliação (KAHAN et al., 2001). 
Para a implementação da proposta de utilizar o MDI de Melhores Práticas, optou-se pelo caminho metodológico da pesquisa-ação. Este apresenta possibilidades de alteração da realidade e de valorização tanto do processo de pesquisa quanto de seus resultados. A pesquisa-ação adota um encaminhamento oposto ao das ciências clássicas, ao ter como finalidade servir de instrumento de mudança social e a produção de conhecimento dos esforços feitos para levar à mudança (BARBIER, 2007). Foram utilizadas técnicas de pesquisa quantitativas e qualitativas, com predominância desta última.

O estudo foi realizado no município de Antônio Carlos, região da Grande Florianópolis (SC), cuja população no ano de 2008 era de 7.375 pessoas. Com um pequeno núcleo urbano, $72,5 \%$ da população se distribuem em pequenas propriedades na zona rural (BRASIL, 2008). A população idosa com 60 ou mais anos é de 929 pessoas, correspondendo a 12,6\% do total, sendo 52\% mulheres. O IDH-M (Índice de Desenvolvimento Humano Municipal) cresceu de 0,731, em 1991, para 0,827, em 2000, ficando o município entre as regiões consideradas de alto desenvolvimento humano (IDH >0,8) e ocupando a $154^{\mathrm{a}}$ posição nacional e a 36 em Santa Catarina (PNUD, 2006). Acompanhando as melhorias observadas nos demais sub-índices, destaca-se o seu IDH-M/ longevidade $(0,882)$ : o município ocupa a segunda posição no ranking nacional, estando atrás apenas de São Caetano do Sul (SP) (PNUD, 2006).

No campo da saúde, o município conta com uma unidade de saúde operada pela prefeitura, onde são dispensados atendimentos de atenção básica à população, inclusive na área odontológica, e algumas especialidades médicas. A ESF cobre todo o município, desde junho do ano 2000, pelo trabalho de três equipes, apenas uma delas cadastrada com ESB.

O serviço público odontológico atende à demanda espontânea na unidade de saúde. Há uma unidade móvel que se dedica principalmente ao atendimento da população infantil nas escolas. Os procedimentos coletivos em odontologia estão focados nas crianças no ambiente escolar. $\mathrm{O}$ atendimento à população idosa se restringe à assistência odontológica oferecida no Centro de Saúde, para procedimentos de atenção básica e palestras nos grupos HiperDia e de convivência. Não é garantida prioridade na marcação de consultas odontológicas para o idoso. 
Fizeram parte da pesquisa 20 pessoas, a saber: 5 idosos, 3 cirurgiões-dentistas (CD), 2 Auxiliares de Saúde Bucal (ASB), 1 Assistente Social, 3 Enfermeiros, 1 Gestor - Coordenador da Saúde, 1 Vereador, 1 Gestor - Secretário de Saúde e 3 Agentes Comunitários de Saúde. A coleta de dados se desenvolveu por meio da aplicação da técnica do grupo focal com discussões criteriosamente planejadas, nas quais os participantes expressaram coletivamente suas percepçôes, crenças, valores, atitudes e representações sociais sobre o objeto deste estudo. A composição dos grupos se deu em função da inserção dos participantes e sua relação com a temática em estudo. Foram constituídos seis grupos focais : Grupo 1 - Idosos; Grupo 2 - Profissionais da saúde bucal; Grupo 3 - Gestores; Grupo 4 - Profissionais da ESF; Grupo 5 - Profissionais da saúde bucal; Grupo 6 Agentes Comunitários de Saúde. As discussões foram registradas em gravador digital e todo o conteúdo foi transcrito, constituindo dados qualitativos brutos. O processo de aplicação do MDI seguiu quatro etapas (KAHAN et al., 2001), descritas a seguir.

\section{Etapa/Momento 1. Preparando os fundamentos para a ação}

a. Identificação dos marcos teóricos que orientam os conceitos de promoção da saúde e saúde pública. A pergunta norteadora foi: o que nos guia? Buscou-se analisar a visão dos participantes em relação a marcos teóricos relevantes para a promoção da saúde geral e bucal, inclusive do idoso.

b. Exame da situação atual. A pergunta norteadora foi: onde estamos? Os participantes consideram os fundamentos, práticas e elementos do ambiente que influenciam no projeto e na organização do sistema de saúde, tanto os conhecidos como os implícitos; identificação de forças, recursos e capacidades; preocupações decorrentes da situação atual; processos para revisar e atualizar os conteúdos;

c. Desenvolvimento de uma imagem da situação ideal. A pergunta norteadora foi: onde queremos chegar? Nesta etapa, procurou-se estabelecer uma visão idealizada daquilo que se deseja alcançar, baseada nos fundamentos identificados e no diagnóstico da situação. 
Etapa/Momento 2. Desenvolvendo o plano de ação e avaliação

Foram elencados: a. Objetivos específicos; b. Recursos; c. Desafios; e d. Mecanismos de monitoramento e avaliação.

Etapa/Momento 3. Implementando a ação e avaliação, refletindo e documentando as atividades, processos e resultados

Constituiu a etapa de formulação e implementação das ações e avaliação. Foi também um momento de reflexão e de documentação do desenrolar do processo, bem como do registro de alguns resultados alcançados ou de resultados esperados.

\section{Etapa/Momento 4. Revisando o objetivo idealizado inicialmente e o plano de ação/avaliação, baseados nos resultados expressos nos documentos gerados}

A pergunta norteadora foi: o que necessitamos alterar para seguir adiante?

Dentro do marco de desenvolvimento do MDI de Melhores Práticas, foi disponibilizado um software próprio, adequado às necessidades dos pesquisadores, de modo a auxiliar na transcrição, registro e visualização dos dados coletados e na construção das planilhas organizadoras do conhecimento revelado/construído. A planilha principal do software foi utilizada como ferramenta para organização e análise dos dados. A partir da leitura dos textos com as transcrições das falas dos grupos, procedeu-se à análise. $\mathrm{O}$ primeiro tratamento dos dados textuais exigiu uma codificação inicial, ou seja, a separação de elementos de significados em tópicos a serem utilizados no preenchimento da planilha principal do MDI.

\section{Resultados}

Os resultados alcançados neste estudo derivam das contribuições que se originaram nos grupos focais, processadas e organizadas segundo o referencial metodológico do MDI de Melhores Práticas. Fruto das interações havidas nos grupos focais, procedeu-se a um conjunto de intervenções que envolveram Melhores Práticas no cuidado à saúde bucal do idoso e que, adicionalmente, compõem os resultados dessa pesquisa-ação. 
O processo de desenvolvimento de Melhores Práticas em Antônio Carlos aplicado nesta pesquisa-ação se fundou na expectativa de que mais elevados padrōes de saúde bucal dos idosos poderão ser alcançados mediante Melhores Práticas de cuidado resultantes da mudança das práticas organizacionais, do processo de trabalho em saúde, de pesquisa e de avaliação. A mudança possível decorre da disposição dos atores envolvidos em refletir e analisar criticamente os comportamentos, procedimentos e situações correntes. Essas práticas são moldadas segundo os fundamentos (valores, objetivos, teorias e conceitos, crenças e evidências) assumidos pelos atores estratégicos posicionados no sistema, filtrados pelas diretrizes e contexto do SUS e da ESF, e pelos princípios da PS. As práticas são influenciadas pelo ambiente em que são produzidas e pelo modo como os atores interpretam e estabelecem sua relação com as circunstâncias do ambiente. A análise e a visão do contexto organizacional em que se dá a produção de saúde dos idosos, e das condições epidemiológicas e de saúde da população, também sob o filtro do SUS, da ESF e dos referenciais da OS, contribuem para a moldagem das práticas de cuidado à saúde bucal do idoso. Na perspectiva de mudanças incrementais, a geração e aplicação de novas e melhores práticas trazem novas energias retroalimentadoras, que ressignificam os fundamentos e a compreensão do ambiente. O vetor de impulsão para a melhoria contínua das práticas organizacionais e de saúde é o compromisso da governança local com os princípios da Promoção da Saúde.

Mesmo num pequeno município, com carência de recursos e de pessoal, foi possível construir um corpo indicativo de práticas e gerar conhecimento útil que aproxima os modelos teóricos com a realidade cotidiana, com vista a sua transformação.

O quadro 1 apresenta, de forma resumida, as categorias de intervenções possíveis indicadas, decorrentes do exercício de reflexão/ação, que mostram quanto frutífero é o trabalho de cunho qualitativo-construtivista, apoiado em sujeitos qualificados e motivados, refletindo e decidindo em favor das organizaçōes às quais pertencem e defendem. Algumas das intervenções indicadas foram realizadas, conforme descrição subsequente. 
domínios do Modelo de Domínios Interativos

\begin{tabular}{|c|c|}
\hline Domínios & Melhores Práticas: intervençóes possíveis \\
\hline $\begin{array}{l}\text { Em } \\
\text { relação aos } \\
\text { Fundamentos } \\
\text { para a ação }\end{array}$ & $\begin{array}{l}\text { Educação permanente; Capacitação de RH e pessoas da comunidade; } \\
\text { Participação comunitária e de idosos nas instâncias de decisão; Ações } \\
\text { de desconstituição de crenças; Difusão de conteúdos de saúde bucal e } \\
\text { de referenciais de PS, SUS, ESF e de evidências; Preparação de material } \\
\text { educativo-informativo; Discussão sobre ética e prática profissional. }\end{array}$ \\
\hline $\begin{array}{l}\text { Em relação à } \\
\text { Compreensão } \\
\text { do ambiente }\end{array}$ & $\begin{array}{l}\text { Definição da visão da organização e da saúde; Descrição e análise } \\
\text { dos processos de trabalho; Estudo e aperfeiçoamento das práticas de } \\
\text { governança local; Análise e criação de ambientes suportivos; Análise } \\
\text { das relações intergovernamentais e atores estratégicos; Implantação } \\
\text { de sistema de informações e documentação sobre condição sócio- } \\
\text { demográfica-epidemiológica, serviços prestados, follow up de usuários, } \\
\text { e gestão de insumos; Planejamento integrado das ações de saúde; } \\
\text { Exercício da prática do acolhimento e atenção humanizada; Articulação } \\
\text { em defesa do sistema local de saúde no âmbito do SUS entre usuários, } \\
\text { trabalhadores e gestores; Garantia da participação dos profissionais } \\
\text { em processos de análise e avaliação dos serviços; Viabilização de } \\
\text { ações intersetoriais; Ampliação e valorização estratégica dos grupos } \\
\text { de convivência de idosos; Realização de eventos com enfoque na } \\
\text { PS; Reorganização do serviço odontológico e definição dos modelos } \\
\text { de atenção; Organização de sistema de agendamento - consultas } \\
\text { programáticas, retornos e urgências; Adoção da lógica da integralidade } \\
\text { no atendimento das necessidades do usuário; Garantia e suporte de } \\
\text { referência e contra-referência; Priorização dos idosos no agendamento } \\
\text { de consultas, inclusive as odontológicas; Estudo de sub-grupos idosos } \\
\text { prioritários; Prontuário de família integrado; Visitação domiciliar } \\
\text { como ação interdisciplinar; Definição do papel da ESB na equipe } \\
\text { de SF; Transporte dos usuários com dificuldade de locomoção ao } \\
\text { CS; Maximização do uso dos recursos de saúde, públicos e privados, } \\
\text { instalados no município; Pensar a cidade na perspectiva da Promoção } \\
\text { da Saúde e do envelhecimento ativo. }\end{array}$ \\
\hline
\end{tabular}




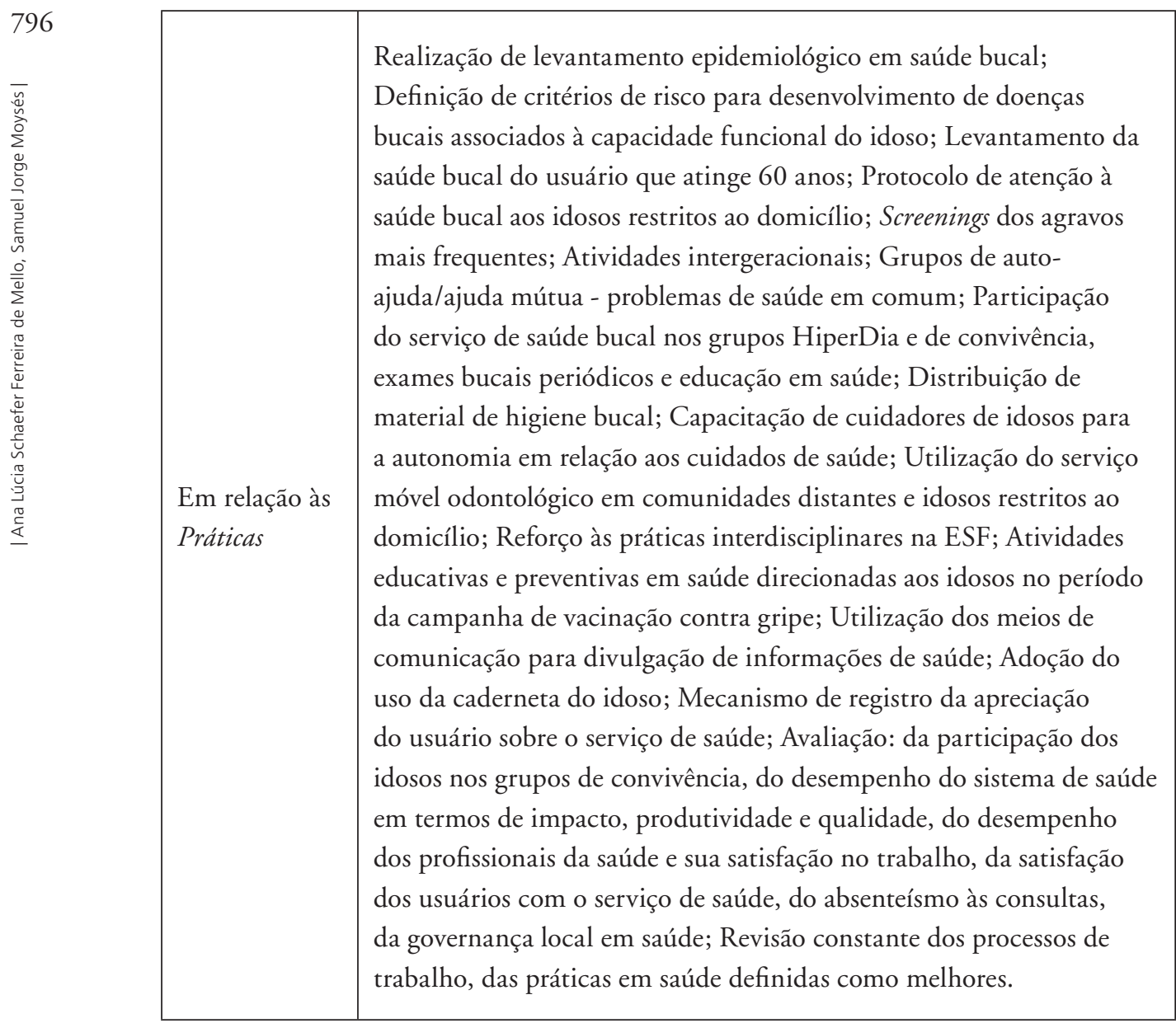

Como ferramenta para a gestão de sistemas ou serviços de saúde, o MDI facilitou a organização da discussão sobre as práticas correntes e a construção participativa de conhecimentos. Aporta uma nova possibilidade tecnológica para desencadear processos de mudanças, desde que haja uma predisposição dos indivíduos, dos coletivos e das organizações. Esta predisposição foi encontrada entre gestores, profissionais da saúde e idosos na realidade estudada, de tal modo que se pôde desenvolver intervenções que consubstanciam Melhores Práticas no cuidado à saúde bucal do idoso.

A seleção dessas intervenções atendeu a indicações dos grupos focais e oportunidade, e concentraram-se nas áreas de organização dos serviços, ambientes 
suportivos e análise da situação de saúde dos idosos, sempre buscando realçar a questão da saúde bucal. Tais intervençōes resultaram do mecanismo decisão-ação descrito pelo MDI de Melhores Práticas, e constituem um bom exemplo de como a ferramenta, se adotada como tecnologia de gestão, pode alavancar novos cenários e contribuições. Foram executados no contexto dessa pesquisa-ação: Avaliação da autopercepção em saúde bucal e utilização de serviços odontológicos por idosos; Mapeamento dos idosos do município, segundo sexo, condição crônica de saúde, por microárea; Levantamento e análise das informações sobre a assistência a idosos pelo serviço odontológico no Centro de Saúde do município, desde 2005 até agosto de 2008; Estudo da governança em saúde e assistência social em Antônio Carlos; Participação em eventos comunitários; Screening para lesões de mucosa em Antônio Carlos, 2008; Capacitação de ACS sobre cuidados à saúde bucal de idosos; Capacitação dos profissionais CD e ASB em ESF; Aplicação dos instrumentos Cidade Amiga do Idoso e Unidade de Saúde Amiga do Idoso.

\section{Discussão}

A partir da realização deste estudo, e independentemente do recorte adotado, constata-se que as práticas de cuidado à saúde bucal do idoso não estão desvinculadas do contexto geral em que ocorrem outras práticas. Há uma reprodução do modelo geral de atenção e assistência à saúde e, por isso, crê-se possível sua análise ser transportada para o conjunto de ações concretizadas no município e, possivelmente, para outros cenários.

A incorporação de melhores práticas de cuidado à saúde bucal do idoso passa pelo modo de produzir saúde por meio da ação dos serviços ofertados à população e, portanto, pela gestão do sistema local de saúde, em articulação com os níveis regional, estadual e nacional, todos subsistemas integrantes da trama que configura o Sistema Único de Saúde brasileiro. Assim, a discussão sobre a melhoria contínua do processo de trabalho em saúde bucal está involucrada na discussão sobre os modelos adotados de atenção e assistência à saúde. Recursivamente, parte-se do ponto ao qual se almeja chegar: a partir da análise dos fundamentos do próprio SUS, deseja-se aperfeiçoar o sistema municipal de saúde tomado como expressão local do SUS - aquele sobre o qual se impõe a responsabilidade e compromisso por tantas questôes de saúde (ou de doença) 
que afetam a vida dos munícipes e nelas incluídas as questões relativas à saúde bucal de todos, e em especial a do grupo dos idosos. O descuido em saúde bucal e a negligência com idosos, além de apontarem para a incompletude da atenção integral à saúde com os custos daí derivados, significam uma disfunção do SUS e uma agressão a seus princípios.

A produção de conhecimento científico, a partir de ensaios nos campos da prática social, procura a aproximação entre planos, que em Odontologia, ainda se mantêm distantes: o plano da teoria, o plano da retórica, o plano das práticas sociais. Neste aspecto, o SUS é um emblema. Esse distanciamento entre o que a evidência científica recomenda, o que se promete fazer e o que efetivamente se faz é observável em diversas áreas e também na saúde bucal. A tecnologia disponível e o corpo de princípios, propósitos e promessas do sistema situam-se bem acima das práticas encontradas. Teoria e prática, ao se visitarem simultânea e continuamente, costumam produzir um espaço de intersecção extremamente produtivo, tanto no que diz respeito ao reforço e potencialização dos embasamentos teórico-explicativos, quanto à concretização do ideal da produção social da saúde da população. As melhores práticas resultam essencialmente da experimentação teórico-prática no cotidiano da gestão e execução dos serviços de saúde.

Dependendo do contexto no qual essas prescrições são apresentadas, o sistema que se considera "local” de saúde tem dificuldades para adaptar suas práticas, mobilizar recursos para implementá-las, tornar mais flexíveis suas estruturas e ser mais permeável à incorporação de novos conhecimentos. Numa dimensão mais focal, observou-se que a saúde bucal dos idosos de Antônio Carlos não é beneficiária do profícuo arsenal de conhecimentos e tecnologias existentes, capazes de converter essa carga teórica em produção e provisão de serviços de saúde. Nesse campo, é muito limitado o acesso aos frutos do progresso técnico e as novas tecnologias de gestão. Constata-se, de um lado, a inadequação da estrutura organizacional vigente, e de outro, de que a comunidade opera modelos assistenciais exogenamente desenhados (PINHEIRO, 2001).

A pesquisa conviveu com um interessante paradoxo. A longevidade do povo antoniocarlense colocou o município em segundo lugar nacional no IDH-longevidade. Em paralelo, segue precária a condição de saúde bucal da população idosa. Embora não se tenha um levantamento epidemiológico, outros 
elementos e informações permitem afirmar que os longos anos de vida estão sendo acompanhados por acentuado edentulismo, progressiva perda dentária, ocorrência elevada de lesões de mucosa oral, inclusive com casos suspeitos de lesões pré-cancerígenas, doenças periodontais, má condição de higiene bucal e de próteses, falta de assistência odontológica on site ao idoso restrito ao domićlio, por crenças e estigmas que excluem o segmento idoso da atenção específica que necessita receber, pela dificuldade de acesso aos serviços públicos odontológicos, pela incapacidade do serviço odontológico para proporcionar atenção integral à saúde bucal, por tradicional omissão do setor público na alocação suficiente de recursos para ações de saúde bucal inclusivas do idoso; por uma iníqua partilha das receitas públicas que impede seu município de dispor de receitas próprias para executar, na ausência da União e do Estado, uma política local de cobertura e reversão destas necessidades acumuladas.

O estilo de vida saudável que tem explicado a longevidade de seus idosos não contempla o conforto dos benefícios que a promoção da saúde e a evidência científica em saúde bucal têm colocado à disposição das pessoas. As teorias, o conhecimento acadêmico, a retórica dos planos e programas de saúde bucal permaneceram distantes do processo que permitiu mais pessoas alcançar longevidade. E, nestas circunstâncias, quanto mais idade foi alcançada, mais aparentes passaram a ser os problemas de saúde bucal, pois as práticas individuais e coletivas e a governança do sistema de saúde não conseguiram acompanhar as necessidades e demandas emergentes, típicas dessa faixa etária.

Esse paradoxo é o alerta que esta pesquisa traz a uma sociedade em acelerado processo de envelhecimento populacional: as pessoas precisam atingir a idade longeva com doenças bucais para terem direito à saúde bucal? A superação do paradoxo reside no esforço coletivo de construção de Melhores Práticas de Promoção da Saúde que contribuam para um bem-envelhecer.

Adicionar questôes relativas à governança dos sistemas locais de saúde que impliquem maior poder à representação social, mudanças estruturais e na gestão de pessoas, monitoramento de prioridades, maior transparência, revisão de procedimentos e compromissos, atualização das relações intergovernamentais, busca de maior resolutividade, entre outras, costuma gerar certo desconforto e insegurança e até resistência nos atores envolvidos. É nesse contexto que se provoca 
um movimento de saída de uma aparente zona de conforto dos serviços de saúde bucal, para a reflexão e consequente desestabilização (no sentido positivo, de quebra de inércias e rotinas) das práticas consideradas tranquilas e dominadas por seus agentes produtores, e até mesmo pela população. A falta de avaliações coletivas periódicas, multiprofissionais, a falta de busca ativa de usuários, não fazem emergir os óbices, identificar as eventuais carências e necessidades, constatar as defasagens. A verificação da necessidade de ajustes nos serviços e práticas gerenciais em saúde bucal não se revela quando há obstrução nos canais de comunicação dos profissionais entre si e destes com as demais áreas. Também os problemas não emergem quando se deixam à margem os procedimentos de planejamento e avaliação, oportunidade em que as pessoas podem colocar suas posiçôes construtivas e orientadas para o agir qualificado. Tais procedimentos valorizam e qualificam a governança e criam canais aceitos, pelos quais deve fluir naturalmente o salutar controle cruzado dos papéis de cada agente no processo de produção da saúde.

$\mathrm{Na}$ análise de Trevisan et al. (2007), a implantação do SUS enfrenta descompassos gerenciais, pois a pressão pela diminuição dos custos compromete o princípio da universalidade, e embora tenha havido pretensamente descentralização de decisões para o nível local, as transferências de recursos não acompanharam este movimento. Agrava as dificuldades da questão do financiamento outro dilema muito próximo: a convivência entre o princípio da descentralização e o conceito de redes de atenção à saúde.

Os esforços sustentados de melhoria de práticas requerem amplo comprometimento de todos os níveis da organização, fato efetivamente complexo no âmbito do serviço público. Segundo os formuladores do MDI, as Melhores Práticas em Promoção da Saúde são construídas quando os processos e atividades associados ao estudo da situação organizacional e de saúde e a condução de pesquisas/avaliação refletem os princípios da PS em cada um dos subdomínios propostos pelo modelo: a) Valores, objetivos e preceitos éticos; b) Fundamentos teóricos/conceitos e crenças; evidência; e c) Visão e análise da organização e da situação de saúde. Nesta perspectiva, cada identificação de ação/procedimento de melhor prática, construída nos grupos focais e ajustada ao contexto estudado, está em conformidade com os princípios da PS em cada subdomínio, nos níveis individual, grupal e organizacional. Em Antônio Carlos, foram identificadas 
zonas de conflito, concordâncias e diferenças, em cada subdomínio, ao mesmo tempo em que foram constantemente revisitados os princípios da PS para assegurar que permaneciam apropriados e relevantes e que se encontravam integrados às práticas propostas. Em geral, conseguiu-se garantir a consistência entre todos os domínios e sub-domínios do modelo (KAHAN et al., 2005).

Os princípios da PS estiveram constantemente balizando os trabalhos. Interessante ressaltar que, grosso modo, os participantes possuíam uma visão bastante abrangente dos referenciais da Promoção de Saúde, reforçado por um entendimento ampliado do conceito de saúde e pelo reconhecimento dos determinantes sociais no processo saúde-doença. Todavia, esta visão não alcançava as práticas intersetoriais e, mesmo, intrassetoriais sobre o processo saúde-doença realizadas pelos serviços, tanto nos níveis individuais como coletivos, e entre gestores, profissionais e usuários idosos. Importante desafio à governança é fazer com que os princípios explicitados individualmente sejam incorporados nos papéis que cada um desempenha no sistema local, reduzindo assim a distância tão comum entre a retórica e a prática. $\mathrm{O}$ uso do instrumental MDI facilita a constatação destas dessintonias, estimula a identificação das causas e promove os esforços para corrigi-las.

Investigações cuja arquitetura metodológica pressupõem uma intervenção, como a presente pesquisa-ação, constituem novas fronteiras de possibilidades de aproximação de referenciais teóricos como o da PS às práticas do cotidiano dos sistemas de saúde. Por meio da aplicação da plataforma de trabalho MDI de Melhores Práticas, que adota os referentes da PS, foi possível revelar práticas específicas (atividades e processos) de cuidado à saúde bucal do idoso que representam clara evolução e melhoria em relação ao padrão geralmente encontrado no nível assistencial: procedimental, baseado em queixa-conduta, medicalizante e tecnicista.

$\mathrm{Na}$ área da saúde bucal em Antônio Carlos, convivem dois modelos de atenção e assistência: o tradicional, focado no atendimento da demanda espontânea (via agendamento dos usuários que buscam o serviço ou pronto-atendimento dos casos de urgência) e o da ESB na ESF, mas com atenção focalizada em escolares. Numa apreciação mais rigorosa, a área da saúde bucal ainda não foi incorporada plenamente à ESF, muito embora venham sendo incorporadas práticas 
compatíveis com as atribuições dos CD e ASB na ESF. Observa-se que a área de saúde bucal não pratica o mesmo processo de trabalho da ESF, incluindo aqui os agentes comunitários de saúde, embora realize atividades educativas pontuais $\mathrm{e}$ em conjunto, como palestras em grupos de idosos e aos cadastrados no HiperDia. No mais, apesar das diferenças de logística e de faixa etária atendida (escolares), em seu âmago o trabalho com a unidade móvel tem a mesma característica do modelo tradicional, fato este apontado pelos próprios profissionais. A prática configura um movimento paralelo à ESF realizada por médicos e pessoal de enfermagem, com poucas possibilidades de contato e integração.

A literatura tem recebido aportes relatando experiências com baixo grau de integração dos serviços prestados pela área da saúde bucal com a ESF (SOUZA et al., 2007). São raros, em contrapartida, os relatos de sucesso na adoção de práticas que possam ser compartilhadas, por possuírem os atributos essenciais dos serviços de atenção primária em saúde, independentemente do modelo adotado: primeiro contato, longitudinalidade, integralidade, coordenação, orientação familiar, abordagem comunitária e competência cultural (STARFIELD, 2002). De todo modo, na perspectiva da aproximação teórico-prática, "a troca de experiências de boas práticas, evidenciadas por estudos avaliativos consistentes, é essencial para a disseminação de estratégias de promoção de saúde na atenção coletiva” (MOYSÉS; KUSMA, 2008).

O processo terapêutico na atenção básica em saúde bucal assume circunstâncias distintas em Antônio Carlos, tanto no CS como no serviço móvel: consulta clínica, atendimento de urgência, retornos programados e encaminhamentos a outros serviços da rede. As ESBs, no caso de Antônio Carlos, os profissionais $\mathrm{CD}$ e o respectivo pessoal auxiliar, imprimem diferentes formas de acolhimento, ficando na dependência do compromisso e da singularidade dos sujeitos. Especificamente em relação ao usuário idoso, não estão superadas as dificuldades para garantir o acesso aos serviços de saúde bucal. Outra questão central em relação às necessidades apresentadas pelos idosos é a baixa resolutividade, à medida que necessitam de atendimento de maior complexidade. Os profissionais do serviço de saúde bucal não possuíam esta mesma percepção, pois limitavam sua análise aos serviços sob sua responsabilidade e como tal consideravam-no resolutivos e de fácil acesso. Esta é uma questão crucial para a população idosa, 
pois não se cumpre o compromisso da resolutividade em relação a todos quantos

necessitam e não se lhes possibilita a oferta de serviços de prótese no sistema. A expectativa colocada nos CEO, neste particular, não se concretizou.

A oferta de atenção básica em saúde bucal é determinada pela capacidade de atenção no serviço móvel e no CS, dados os equipamentos instalados e o número de horas/CD semanais contratadas, bem como pela organização dos serviços e ação-resposta dos profissionais CDs. A demanda dos idosos ao CS se constitui espontaneamente, geralmente encaminhada pela dor causada por um problema agudo e menos por um comportamento de rotina de cuidado. Por sua vez, as necessidades em saúde bucal dos idosos merecem um olhar para seus elementos constituintes. O conjunto potencial de necessidades em saúde bucal dos idosos foi continuadamente abafado, normativa e socialmente, pelos estigmas e crenças produzidos no seio da sociedade e reproduzido no interior dos serviços de saúde. O conceito de necessidade, para Stotz (1991), é um conceito de junção, que deve ser compreendido no interior das práticas sociais, no contexto de suas mediações fundamentais, pertinentes às "relaçôes entre sujeitos de necessidades e sistema institucional-administrativo responsável por sua satisfação" (AZEVEDO, 2007, p. 45). A aplicação do MDI procurou resgatar esta relação, caracterizando as necessidades em saúde bucal dos idosos pela expressão dos diferentes grupos gestores, profissionais, idosos e o modo como o sistema se apresenta disposto a lidar com elas. A percepção das necessidades, sejam elas reais ou potenciais, ainda é muito superficial, e por isso a resposta também é assim estruturada. Não se percebe uma compreensão mais clara de que "as dificuldades sentidas pela população na busca pelo serviço de que necessita fazem-na desenvolver modos próprios de utilização dos serviços" (AZEVEDO, 2007, p. 43). O fato de que o cuidado preventivo é esquecido e inexiste busca ativa gera um conjunto de necessidades de atenção de mais alta complexidade cuja produção se dá com muita dificuldade fora do território, ainda que dentro do sistema local de saúde simplesmente não seja ofertado, como no caso dos serviços de prótese dentária. Essa circunstância é colocada como hipótese para explicar a reduzida manifestação de demanda por idosos nas portas das unidades de saúde.

Nesse contexto, o paradigma da Promoção da Saúde, identificado nas letras do SUS e da ESF, inspira a alteração da lógica presente da oferta e da demanda pela 
força concreta dos seus preceitos na desejável reordenação do sistema de saúde e em consequência na evolução para modelos assistenciais que sejam mais resolutivos, integrais e equânimes. As melhores práticas no cuidado à saúde bucal das pessoas idosas aqui formuladas preveem a concretização do princípio da integralidade a partir de mudanças baseadas numa percepção ampliada das necessidades desse grupo e na predisposição para as melhores formas de dar respostas a tais necessidades. Toma a integralidade como um referencial a ser seguido no modo de organização do processo de trabalho dos $\mathrm{CD}$, e demais profissionais da saúde, e no sentido de ver o impacto epidemiológico de suas ações.

O sistema de agendamento adotado, se de um lado acelera a entrada no sistema (primeira consulta), de outro compromete a saída na medida em que o retorno não é assegurado em prazo tecnicamente satisfatório, salvo situações pontuais. Assim, a responsabilização pelo princípio da integralidade, de fato, acaba sendo transferida do sistema de saúde para o indivíduo idoso. E em cascata perde-se a possibilidade de atenção integral, bem como de seus dispositivos: acolhimento, vínculo, autonomia, resolutividade, responsabilização (SANTOS et al., 2006). A reboque desta situação vem a autopercepção dos idosos sobre a sua condição de saúde bucal e o consequente padrão de utilização dos serviços. O presente estudo mostra que os idosos percebem como boa sua saúde bucal, embora os levantamentos epidemiológicos demonstrem o contrário daquilo que é percebido. A avaliação parece ser influenciada por fatores como renda, necessidade de tratamento odontológico, utilização de serviços odontológicos, dor e condições de saúde bucal; condiçôes subjetivas estão mais fortemente associadas do que objetivas (MARTINS et al., 2009).

O desenvolvimento de Melhores Práticas por meio da ferramenta MDI constituiu aqui um movimento de aprendizagem no interior de uma organização de saúde. Atualmente, as discussões sobre aprendizagem organizacional superam as barreiras puramente teóricas e alcançam questionamentos sobre a real capacidade de interferência em níveis práticos de mudanças estruturais nas organizaçôes. Mais do que criar e adquirir conhecimento, o desafio é aplicar esses conhecimentos nas suas atividades e, mais ainda, transformar esse investimento, que é pessoal e coletivo, em melhorias reais (GREEN, 2001). Assim, a incorporação de novas práticas está comprometida especialmente com questôes relativas à gestão de pessoal (MCCORMICK et al., 2006). O investimento e estímulo à educação permanente e o monitoramento e avaliação 
das ações por eles desenvolvidas apontam um redirecionamento do modelo assistencial em saúde bucal. $\mathrm{Na}$ visão de Campos (2006), a viabilização do SUS não pode se basear na subordinação dos trabalhadores de saúde a métodos administrativos. Há que se considerar os trabalhadores da saúde os verdadeiros sujeitos no processo de mudança, incluí-los ao lado de gestores e usuários como protagonistas dos processos de decisão-ação-avaliação.

A abordagem dos problemas de saúde dos idosos envolve, também, a formulação de políticas econômicas, previdenciárias, de educação, de saneamento básico, de segurança e habitação, enfim, de desenvolvimento sustentável e inclusivo da comunidade. E ainda a permanência em atividade laboral, potencialização das atividades comunitárias, melhoria nos estilos de vida, adaptação do sistema de saúde às necessidades dos idosos, especialmente em ações preventivas com relação custo-benefício positiva e embasadas em evidência (OECD, 2009).

Estudos têm demonstrado a ineficiência dos modelos tradicionais de assistência ao idoso (LOURENÇO et al., 2005; PICCINI et al., 2006) e na concretização do ideal do envelhecimento bem sucedido. A partir dessa constatação, e em consonância com os fundamentos da Promoção da Saúde, é que se entende o fortalecimento do SUS e da ESF na consolidação de práticas de envelhecimento saudável e ativo. Embora ainda distante do desejado, as unidades que operam na lógica da SF se revelam mais adequadas para atenderem a população idosa do que as unidades tradicionais (PICCINI et al., 2006).

Importante destacar que, na perspectiva da produção de melhores práticas em saúde da família, o estabelecimento de ações de promoção do cuidado à saúde bucal dos idosos extrapola o argumento cronológico e proporciona benefícios não somente aos idosos de hoje, mas principalmente, aos idosos do futuro. Além disso, a abordagem multigeracional e intergeracional traz novos construtos sobre a possibilidade de ser o núcleo familiar a base forte das relações sociais, de modo que o idoso é agente também de saúde de cada membro da família (KOCH FILHO et al., 2008).

\section{Considerações finais}

As Melhores Práticas identificadas não são exógenas ao sistema local e foram construídas a partir da reflexão sistemática e crítica dos atores envolvidos com a governança local. Portanto, não dizem respeito à transposição de práticas 
idealizadas que desconsideram a variedade de situações da realidade local, e podem não ser adequadas/adaptadas em circunstâncias singulares. Todavia, estão articuladas aos critérios e princípios da Promoção da Saúde, o que lhes confere atributos para inspirar sua difusão e experimentação, ajustadas a outros contextos. O MDI estimulou a ampla participação e a reflexão sobre as práticas vigentes com o intuito de promover seu aperfeiçoamento em favor dos idosos. Como a participação e o envolvimento das pessoas nas discussōes, decisōes e açōes constituem o fundamento metodológico do MDI na construção de Melhores Práticas de Promoção da Saúde, o trabalho com os grupos focais possibilitou um espaço de reflexão na/sobre a ação e permitiu a produção de informações ricas e aprofundadas sobre a prática profissional e experiências dos participantes, todos envolvidos no contexto do sistema de saúde local. Foi possível captar suas visões, percepções, descrições, análises, críticas, tanto em consenso como em dissenso. Também foram observadas contradiçôes nos discursos: nada mais aderente à complexidade do real. As atividades e processos de Melhores Práticas no cuidado à saúde bucal do idoso desenvolvidas nos grupos focais constituem um vasto e rico rol de propostas que pode ser considerado um "mapa" de orientação ou "cardápio" de possibilidades a ser refinado para uso operacional em contextos determinados.

\section{Referências}

AZEVEDO, A. L. M. Acesso à atenção à saúde no SUS: o PSF como (estreita) porta de entrada. 2007. Dissertação (Mestrado em Saúde Pública) - Centro de Pesquisas Aggeu Magalhães, Fundação Oswaldo Cruz, Recife, 177p.

BARBIER, R. A pesquisa ação. Brasília: Líber Livro, 2007. 159p. (Série Pesquisa, v. 3).

BOTAZZO, C. Sobre a bucalidade: notas para a pesquisa e contribuição ao debate. Ciênc. Saúde Coletiva, v. 11, n. 1, p. 7-17, 2006.

BRASIL. MINISTÉRIO DA SAÚDE. Secretaria de Atenção à Saúde. Departamento de Atenção Básica. Saúde Bucal. Cadernos de Atenção Básica, n. 17. Brasília: Departamento de Atenção Básica, 2006.

BRASIL. MINISTÉRIO DA SAÚDE. DATASUS. Informações em saúde. Dados demográficos. Disponível em <http://tabnet.datasus.gov.br/cgi/deftohtm.exe?ibge/cnv/poptSC>.def Acesso em: 23 dez. 2008.

CAMPOS, G.W.S. Reforma da reforma: repensando a saúde. 3.ed. São Paulo: Hucitec, 2006. 220p. 
CHAVES, S.C.L.; VIEIRA-DA-SILVA, L.M. Oral health care and health decentralization in Brazil: two case studies in Bahia State. Cad Saúde Pública, v. 23, n. 5, p. 1119-1131, 2007. FERREIRA, A.A.A.; PIUVEZAM, G.; WERNER, C.W. A. et al. A dor e a perda dentária: representações sociais do cuidado à saúde bucal. Ciênc. Saúde Coletiva, v. 11, n. 1, p. 211218, 2006.

GREEN, L.W. From research to "best practices" in other settings and populations. Am J Health Behav, v.25, n.3, p. 165-178. 2001.

HUFTY, M.; BÁSCOLO, E.;BAZZANI, R. Gobernanza en salud: un aporte conceptual y analítico para la investigación. Cad Saúde Pública, v. 22, supl., p. S35-S45, 2006.

IBANHES, L. C. HEIMANN, L.S.; JUNQUEIRA, V. et al. Governança e regulação na saúde: desafios para a gestão na Região Metropolitana de São Paulo, Brasil. Cad Saúde Pública, v. 23, n. 3, p. 575-584, 2007.

KAHAN, B.; GOODSTADT, M. Health promotion: developing and implementing a best practices approach to health promotion. Health Prom Practice, v. 2, n. 1, p. 43-67, 2001.

KAHAN, B., GOODSTADT, M. The IDM manual: Basics. 3.ed. Centre for Health Promotion, University of Toronto, May 2005.

KISSLER, L.; HEIDEMANN, F.G. Governança pública: novo modelo regulatório para as relaçôes entre Estado, mercado e sociedade?. Rev Adm Pública, v.40, n.3, p. 479-499, 2006.

KOCH FILHO, H.R.; BISINELLI, J.C. Abordagem de famílias com idosos. In: MOYSÉS, S.T.; KRIGER, L.; MOYSÉS, S.J. Saúde bucal das famílias: trabalhando com evidências. São Paulo: Artes Médicas, 2008. 308p. Cap. 8.5.

LOURENCO, R.A.; MARTINS, C.S.F.; SANCHEZ, M.A.S. et al. Assistência ambulatorial geriátrica: hierarquização da demanda. Rev Saúde Pública, v. 39, n. 2 , p. 311-318, 2005. MARIÑO, R. Oral health of the elderly: reality, myth, and perspective. Bull Pan Am Health Organ, v. 28, n. 4, p. 202-210, 1994.

MARTINS, A.M.E.B.L.; HAIKAL, D.S.; PEREIRA, S.M. et al. Uso de serviços odontológicos por rotina entre idosos brasileiros: Projeto SB Brasil. Cad Saúde Pública, v. 24, n. 7, p. 1651-1666, 2008.

MARTINS, A.M.E.B.L; BARRETO, S.M.; PORDEUS, I.A. Auto-avaliação de saúde bucal em idosos: análise com base em modelo multidimensional. Cad Saúde Pública, v. 25, n. 2, p. 421-435, 2009.

MCCORMICK, R.J.; LANGFORD, J.W. Attitudes and opinions of NHS general dental practitioners towards clinical governance. Br Dent J, v. 200, n. 4, p. 214-217, 2006.

MELLO, A.L.S.F.; ERDMANN, A.L. Revelando contradições e incorporando melhores práticas no cuidado à saúde bucal de idosos. Physis, v. 17, n. 1, p. 139-156, 2007. 
MOYSÉS, S.T.; KUSMA, S. Promoção de Saúde e intersetorialidade na abordagem familiar. In: MOYSÉS, S.T.; KRIGER, L.; MOYSÉS, S.J. Saúde bucal das famílias: trabalhando com evidências. São Paulo: Artes Médicas, 2008. 308p. cap.9.

NARVAI, P.C.; FRAZAO, P.; RONCALLI, A.G. et al. Dental caries in Brazil: decline, polarization, inequality and social exclusion. Rev Panam Salud Publica, v. 19, n. 6, p. 385-393, 2006.

ORGANISATION FOR ECONOMIC CO-OPERATION AND DEVELOPMENT. HEALTH COMMITTEE. Directorate for employment, labour and social affairs. Policies for aging: an overview. OECD Health Working papers n. 42. Paris: Head of Publications SERVICES OECD, 2009. 32p.

PICCINI, R.X.; FACCHINI, L.A.; TOMASI E. et al. Necessidades de saúde comuns aos idosos: efetividade na oferta e utilização em atenção básica à saúde. Ciênc Saúde Coletiva, v. 11, n. 3, p. 657-667, 2006.

PINHEIRO, R. As práticas do cotidiano na relação oferta e demanda dos serviços de saúde. In: PINHEIRO, R.; MATTOS, R.A. (Org.). Os sentidos da integralidade na atenção e no cuidado à saúde. Rio de Janeiro: Cepesc, 2001. 178p.

PROGRAMA DAS NAÇÕES UNIDAS PARA O DESENVOLVIMENTO. Atlas de desenvolvimento humano no Brasil. Disponível em: <http://www.pnud.org.br/atlas/textos_ analiticos/index.php> Acesso em: 15 jul. 2006.

SA, M.C. Subjetividade e projetos coletivos: mal-estar e governabilidade nas organizações de saúde. Ciênc Saúde Coletiva, v. 6, n. 1, p. 151-164, 2001.

SANTOS, A.M.; ASSIS, M.M.A. Da fragmentação à integralidade: construindo e (des) construindo a prática de saúde bucal no Programa de Saúde da Família (PSF) de Alagoinhas, BA. Ciênc Saúde Coletiva, v. 11, n. 1, p. 53-61, 2006.

SANTOS, M.H.C. Governabilidade, governança e democracia: criação de capacidade governativa e relações executivo-legislativo no Brasil pós-Constituinte. Dados, v. 40, n. 3, p. 335-376, 1997.

SOUZA, T.M.S; RONCALLI, A.G. Saúde bucal no Programa Saúde da Família: uma avaliação do modelo assistencial. Cad Saúde Pública, v. 23, n. 11, p. 2727-2739, 2007.

STARFIELD, B. Atenção primária: equilíbrio entre necessidades de saúde, serviços e tecnologia. Brasília: UNESCO, Ministério da Saúde, 2002. 726p.

TREVISAN, L. N.; JUNQUEIRA, L. P. Construindo o "pacto de gestão" no SUS: da descentralização tutelada à gestão em rede. Ciênc Saúde Coletiva, v. 12, p. 893-902, 2007.

WESTPHAL, M.F. Promoção da saúde e prevenção de doenças. In: CAMPOS, G.W.S.; MINAYO, M.C.S.; AKERMAN, M. et al. Tratado de saúde coletiva. São Paulo: Hucitec, 2006. 


\section{Best practices in local health systems: focusing on the elderly's oral health}

This study aimed to apply the best practices for the elderly's oral health care through the theoreticalmethodological framework "Interactive Domain Model of Best Practices in Health Promotion”, which considers the interaction of domains (Underpinnings, Understanding of the Environment and Practice), as an action-research. An intervention at the Best Practice referential in a local health system was carried out through a systematic and critical reflection by the actors involved with local governance, examining its potential to transform current practices according to the principles of Health Promotion. Data were collected from focal groups formed by managers, health professionals and the elderly (20 subjects). The best practices were suggested built on the principles of the National Health Service, Family Health Strategy and Health Promotion. The process of development of Best Practices is based on the expectation that a higher oral health standard for the elderly could be reached by means of a change in organizational practices, as well as in health, research and evaluation practices. The possible change depends on the willingness of the actors involved as regards the careful consideration and analysis of current behaviors, procedures and scenarios. The driving force for the continuous improvement of practices is the commitment of the local governance with the principles of Health Promotion. It was possible to build an indicative set of practices on oral health of the elderly and to generate useful knowledge to afford the approach of the theoretical models to the reality, with a view to the transformation of such practices.

> Key words: health care, elderly's health, oral health, health services for the elderly, health systems, Health Promotion. 